\title{
Prolonged exposure of Stenotrophomonas maltophilia biofilms to trace levels of clofibric acid alters antimicrobial tolerance and virulence
}

\author{
I.B. Gomes a , M.M. Querido ${ }^{\text {b, c }}$, J.P. Teixeira ${ }^{\text {b, c }}$, C.C. Pereira ${ }^{\text {b. c }}$, L.C. Simões ${ }^{\text {d }}$, M. Simões ${ }^{\text {a, * }}$ \\ a LEPABE, Department of Chemical Engineering, Faculty of Engineering, University of Porto, Rua Dr. Roberto Frias, s/n, 4200-465, Porto, Portugal \\ ${ }^{\mathrm{b}}$ Department of Environmental Health, Portuguese National Institute of Health DR. Ricardo Jorge, Rua Alexandre Herculano, 321, 4000-055, Porto, Portugal \\ ${ }^{c}$ EPIUnit - Institute of Public Health, University of Porto, Rua das Taipas, 135, 4050-600, Porto, Portugal \\ d CEB-Centre of Biological Engineering, University of Minho, Campus de Gualtar, 4710-057, Braga, Portugal
}

\section{H I G H L I G H T S}

- Non-antibiotic drugs, including clofibric acid (CA) can affect bacterial behavior.

- The presence of CA in water increased S. maltophilia tolerance to erythromycin.

- CA exposure increased biofilm tolerance to chorine.

- CA exposure decreased S. maltophilia ability to adhere and internalize HT29 cells.

\section{A R T I C L E I N F O}

\section{Article history:}

Received 17 April 2019

Received in revised form 13 June 2019

Accepted 24 June 2019

Available online 25 June 2019

Handling Editor: Jian-Ying Hu

\section{Keywords:}

Antimicrobial resistance

Biofilms

Clofibric acid

Disinfection

Emerging contaminants

HT-29 cell adhesion and internalization
G R A P H I C A L A B S T R A C T

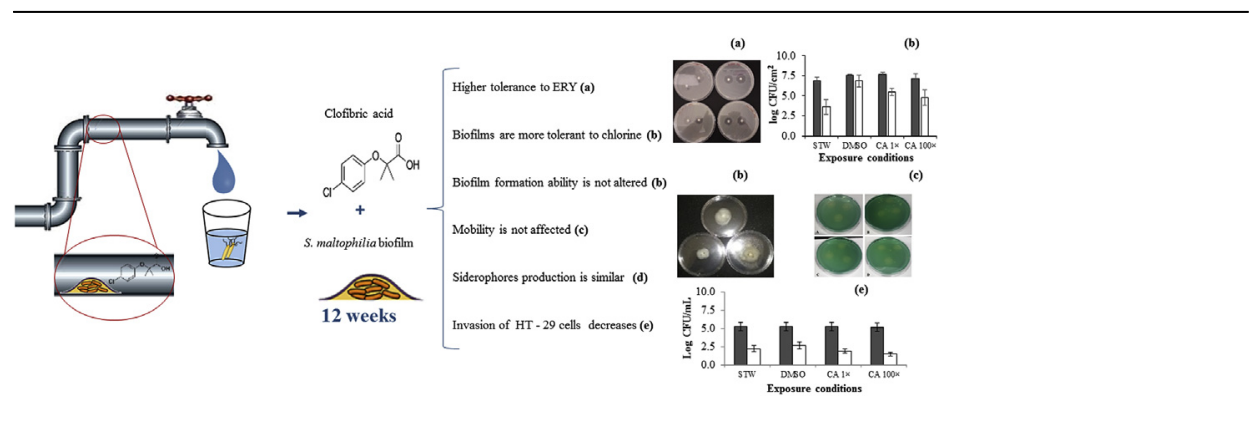

\begin{abstract}
A B S T R A C T
The presence of pharmaceuticals in water sources, including in drinking water (DW), is increasingly being recognized as an emerging and global concern for the environment and public health. Based on the principles of the "One Health" initiative, the present work aims to understand the effects of clofibric acid (CA), a lipid regulator, on the behavior of a selected bacterium isolated from drinking water (DW). Biofilms of the opportunistic pathogen Stenotrophomonas maltophilia were exposed to CA for 12 weeks at 170 and $17000 \mathrm{ng} / \mathrm{L}$. The effects of CA were evaluated on planktonic S. maltophilia susceptibility to chlorine and antibiotics (amoxicillin, ciprofloxacin, erythromycin, kanamycin, levofloxacin, oxacillin, spectinomycin, tetracycline and trimethoprim-sulfamethoxazole), biofilm formation, motility, siderophores production and on the adhesion and internalization of the human colon adenocarcinoma cell line (HT-29). It was found that CA did not affect planktonic S. maltophilia tolerance to chlorine exposure. Additionally, no effects were observed on biofilm formation, motility and siderophores production. However, biofilms formed after CA exposure were more tolerant to chlorine disinfection and lower CFU reductions were obtained. Of additional concern was the effect of CA exposure on S. maltophilia increased tolerance to erythromycin. CA exposure also slightly reduced $S$. maltophilia ability to invade HT-29 cells. In conclusion, this work reinforces the importance of studying the effects of non-antibiotic contaminants on the behavior of environmental microorganisms, particularly their role as drivers affecting resistance evolution and selection.
\end{abstract}

๑) 2019 Elsevier Ltd. All rights reserved.

\footnotetext{
* Corresponding author.

E-mail address: mvs@fe.up.pt (M. Simões).
} 


\begin{tabular}{|llll|}
\hline \multicolumn{2}{ll}{ List of abbreviations } & EA & Ethacrynic acid \\
& & EC & Emerging contaminant \\
$2,4-D$ & $2,4-$ dichlorophenoxycetic acid & ERY & Erythromycin \\
AMO & Amoxicillin & FBS & Fetal bovine serum \\
ARB & Antimicrobial resistant bacteria & GAC & Granular activated carbon \\
ARG & Antimicrobial resistant genes & IBP & Ibuprofen \\
CA & Clofibric acid & KAN & Kanamycin \\
CAS & Chrome azurol solution & LEV & Levofloxacin \\
CBZ & Carbamazepine & MBC & Minimum bactericidal concentration \\
CFU & Colony-forming unit & OXA & Oxacillin \\
CIP & Ciprofloxacin & PBS & Phosphate buffered saline \\
CLSI & Clinical and Laboratorial Standards Institute & PVC & Polyvinyl chloride \\
DMSO & Dimethyl sulfoxide & SPE & Spectinomycin \\
DPD & N,N-diethyl-p-phenylenediamine & STW & Synthetic tap water \\
DW & Drinking water & TET & Tetracycline \\
DWDS & Drinking water distribution systems & TMP & SMX - Trimethoprim - sulfamethoxazole \\
DWTP & Drinking water treatment plant & WWTP & Wastewater treatment plant \\
& & & \\
\hline
\end{tabular}

\section{Introduction}

Non-regulated substances are consistently detected in aquatic environments at trace levels and constitute an emerging environmental concern. These substances have been designated as emerging contaminants (ECs) and are typically defined as synthetic or naturally occurring molecules or drug-resistant microorganisms that are not monitored or regulated, but are found in environmental matrices at trace levels (Geissen et al., 2015; Matamoros et al., 2016). These are indispensable for actual society lifestyle and their use and production can hardly be reduced. There is a wide variety of ECs that have been found in the environment such as detergents, fragrances, pesticides, plastics, endocrine disruptors and other pharmaceuticals and many other compounds. Antibiotic resistant bacteria (ARB) and genes (ARG) and disinfection byproducts are also considered ECs (Geissen et al., 2015; Matamoros et al., 2016). The presence of ARB and ARG may result from the exposure to other ECs, such as antibiotics or other antimicrobials. Their sub-lethal doses found in the environment can induce antibiotic resistance (Geissen et al., 2015; Matamoros et al., 2016). They may reach water sources by several routes. For example, pharmaceuticals are not completely metabolized by humans and animals being then excreted. Therefore, they enter directly in sewage and soil, and consequently reach wastewater treatment plants and groundwater (Kummerer, 2001). Effluents of fish farms are another direct source of ECs for surface water (Kim et al., 2017). However, conventional wastewater treatment processes fail in removing ECs (Huber et al., 2005; Rigobello et al., 2013; Zhang et al., 2017; Delgado-Moreno et al., 2019; Rizzo et al., 2019). Taking into account that drinking water (DW) is often produced from surface water and groundwater, the efficacy of ECs removal through drinking water treatment plants (DWTPs) is of utmost importance. Some conventional treatments in DWTPs, such as filtration, oxidation and adsorption, may remove some of these contaminants. Several studies demonstrated that oxidative processes particularly the use of chlorine are important strategies to reduce ECs levels in DWTPs (Rigobello et al., 2013; Gabarrón et al., 2016). The use of granular filters, such as sand, is also a common strategy applied in DWTPs with low ability to remove ECs (Pojana et al., 2011; Gabarrón et al., 2016). Gabarrón et al. (2016) demonstrated that high removal rates were obtained only for ECs with $\log \mathrm{K}_{\mathrm{w}}$ higher than 3 . In order to increase the efficiency of the granular filtration process, a new barrier can be applied in DWTPs: biofiltration. The presence of biofilms as filters are potentially important to reduce the presence of ECs in DW as microorganisms may degrade ECs (Zearley and Summers, 2012) or increase its adsorption on the matrix of extracellular polymeric substances of biofilms (Petropavlovskii and Sillanpää, 2013; Torresi et al., 2017). The use of granular activated carbon (GAC) is also a conventional strategy used in DWTPs with important results in the reduction of ECs content (Pojana et al., 2011; Rigobello et al., 2013; Gabarrón et al., 2016). Despite all these barriers presented along conventional DWTPs, the removal of ECs is still inefficient and their presence in final DW remains unavoidable (Tröger et al., 2018).

Biofilm formation along the DWDS is another unavoidable phenomenon that may have significant influence on the spread of ARB and ARG (Simões and Simões, 2013; Zhang et al., 2018). These biofilms are continuously exposed to the ECs persisting in the final DW (Wang et al., 2019). The presence of ECs and biofilms in DWDS should be considered based on a One Health approach aiming to improve public health outcomes, recognizing that human health is connected with animal health and the environment -where both are inserted (Gibbs, 2014; Smith et al., 2019). The One Health approach also focus on antimicrobial resistance transmission between humans and animals and in the potential of the environment as source of ARG and ARB (Smith et al., 2019).

This work aims to understand the effect of a selected EC on the behavior of the opportunistic pathogen Stenotrophomonas maltophilia isolated from DW. Clofibric acid (CA) is a lipid regulator used to control cholesterol levels in the blood and has been identified for decades in effluents from domestic wastewater treatment plants (WWTPs), in surface and ground water as well as in DW (Heberer and Stan, 1997; Jux et al., 2002; Zwiener and Frimmel, 2004). CA was found to persist in the environment over 21 years and is still detected in water bodies after being withdraw from the market (Buser et al., 1998; Nega et al., 2019). A previous work evaluated the effects of different ECs (alone and combined) on the behavior of bacteria isolated from a DWDS where it was found that CA was present in all the combinations causing changes in bacterial behavior, particularly biofilm formation ability and tolerance to chlorine disinfection (Gomes et al., 2018a). Therefore, CA was selected for this study, where a prolonged exposure (12 weeks) of S. maltophilia to the EC was evaluated in terms of susceptibility to chlorine and antibiotics, biofilm formation and tolerance to disinfection, siderophores production, motility and invasion of the human colon cancer cell line HT-29. To our knowledge, this is the first work studying the effects of ECs and particularly CA on bacterial production of virulence factors, including adhesion and invasion of 
human cells, providing preliminary insights on the infectious potential from CA exposure.

\section{Materials and methods}

\subsection{Bacterium}

Stenotrophomonas maltophilia previously isolated from a DWDS (Simões et al., 2007), was grown at $25^{\circ} \mathrm{C}, 120 \mathrm{rpm}$ agitation, using R2A broth [0.5 g/L peptone (Oxoid, Hampshire, England), $0.5 \mathrm{~g} / \mathrm{L}$ glucose (CHEM-LAB, Zedelgem, Belgium), $0.1 \mathrm{~g} / \mathrm{L}$ magnesium sulfate heptahydrate (Merck, Darmstadt, Germany), $0.3 \mathrm{~g} / \mathrm{L}$ sodium pyruvate (Fluka, Steinheim, Germany), $0.5 \mathrm{~g} / \mathrm{L}$ yeast extract (Merck, Darmstadt, Germany), $0.5 \mathrm{~g} / \mathrm{L}$ casein hydrolysate (Oxoid, Hampshire, England), $0.5 \mathrm{~g} / \mathrm{L}$ starch (Sigma-Aldrich, Steinheim, Germany) and $0.4 \mathrm{~g} / \mathrm{L}$ di-potassium phosphate trihydrate (Aplichem Panreac, Darmstadt, Germany]. S. maltophilia was selected for this study as it is an emergent opportunistic pathogen frequently isolated from DW and demonstrated to be tolerant to chlorine exposure (Ortolano et al., 2008; Shih and Lin, 2010; Guyot et al., 2013; Vincenti et al., 2014; Amoli et al., 2017a). A previous study demonstrated that the planktonic and sessile behavior of the selected strain was influenced by the exposure to ECs (Gomes et al., 2018a).

\subsection{Substratum}

Polyvinyl chloride (PVC) coupons (Neves \& Neves, Portugal) with $1 \mathrm{~cm} \times 1 \mathrm{~cm}$ were used as substratum for biofilm formation. Before use, the coupons were cleaned and sterilized as described by Gomes et al. (2018a).

\subsection{Clofibric acid}

Stock solutions of clofibric acid (CA; Acros Organics, New Jersey, USA) were prepared in dimethyl sulfoxide (DMSO) (Fisher Scientific, Leicestershire, UK) and stored at $-20^{\circ} \mathrm{C}$ until use. Stock solutions were prepared at $0.017 \mathrm{mg} / \mathrm{L}$ and $1.7 \mathrm{mg} / \mathrm{L}$ in order to use low DMSO volume in biofilms. Stock solutions were diluted 100 times in synthetic tap water (STW) in order to obtain the final concentrations to be tested: 170 and $17000 \mathrm{ng} / \mathrm{L}$. The concentration of DMSO in the final solution was $1 \%$. STW $\left(100 \mathrm{mg} / \mathrm{L} \mathrm{NaHCO}_{3}\right.$, $13 \mathrm{mg} / \mathrm{L} \mathrm{MgSO}{ }_{4} \cdot 7 \mathrm{H}_{2} \mathrm{O}, 0.7 \mathrm{mg} / \mathrm{L} \mathrm{K}_{2} \mathrm{HPO}_{4}, 0.3 \mathrm{mg} / \mathrm{L} \mathrm{KH}_{2} \mathrm{PO}_{4}, 0.01 \mathrm{mg} /$ $\mathrm{L}\left(\mathrm{NH}_{4}\right)_{2} \mathrm{SO}_{4}, 0.01 \mathrm{mg} / \mathrm{L} \mathrm{NaCl}, 0.001 \mathrm{mg} / \mathrm{L} \quad \mathrm{FeSO}_{4} \cdot 7 \mathrm{H}_{2} \mathrm{O}, 1 \mathrm{mg} / \mathrm{L}$ $\mathrm{NaNO}_{3}, 27 \mathrm{mg} / \mathrm{L} \mathrm{CaSO} 4,1 \mathrm{mg} / \mathrm{L}$ humic acids) was prepared as described by EPA (2011) and Gomes et al. (2018a).

\subsection{PVC coupons colonization}

The cell density of bacterial suspensions grown as described in section 2.1 was adjusted to $1 \times 10^{8} \mathrm{CFU} / \mathrm{mL}$ with R2A broth. Then, $1 \mathrm{~mL}$ suspension was added to each well of a 48-wells microtiter plate containing sterile PVC coupons. Coupons colonization with S. maltophilia occurred for $24 \mathrm{~h}$ incubated at $25^{\circ} \mathrm{C}$ and under $120 \mathrm{rpm}$ agitation.

\subsection{S. maltophilia biofilms exposure to $C A$}

The exposure to CA was performed according to Gomes et al (2018b), with few modifications. Briefly, colonized PVC coupons were exposed to CA for 12 weeks in 48-wells microtiter plates. Biofilms were formed for 12 weeks. This incubation period was based on the fact that DW biofilms are developed under oligotrophic conditions, taking several weeks/months to reach a mature state (Abe et al., 2012; Abberton et al., 2016). The biofilms were formed under continuous exposure to DW-containing trace levels of ECs. Two controls were performed: (1) biofilms were grown only in the presence of STW for 12 weeks; (2) biofilms were exposed to $1 \%$ DMSO (solvent control) for 12 weeks. The exposure to CA was performed at two concentrations, an environmental concentration similar to those found in DW distribution systems (DWDS) ([DW] $170 \mathrm{ng} / \mathrm{L}$ ) (Jones et al., 2005) and a concentration one hundred times higher $(100 \times[\mathrm{DW}]-17000 \mathrm{ng} / \mathrm{L})$. The solutions were replaced every week, in order to guarantee a constant exposure to trace CA concentrations.

\subsection{S. maltophilia characterization after prolonged exposure to $C A$}

After biofilm exposure to CA for 12 weeks, S. maltophlia cells from biofilms were recovered in R2A agar (Oxoid, Hampshire, England) plates before further tests to characterize the susceptibility of planktonic cells to chlorine and antibiotics. CA-exposed cells were also used to form biofilms and these were tested on their susceptibility to chlorine. Further experiments were performed to characterize bacterial motility, siderophores production and the adhesion and invasion of HT-29 cells.

\subsubsection{Susceptibility to chlorine}

The bacterial suspension from CA-exposed biofilms was centrifuged (15 min, $3700 \mathrm{~g}$ ) and resuspended in STW to a final concentration of $1 \times 10^{6}$ cells $/ \mathrm{mL}$, in order to mimic DWDS conditions (Prest et al., 2016). S. maltohilia was exposed to different concentrations of free chlorine $(1-10 \mathrm{mg} / \mathrm{L})$, prepared with $\mathrm{NaOCl}$ (Sigma-Aldrich, Steinheim, Germany) for $24 \mathrm{~h}$ in a 96 wells microtiter plate. Free chlorine concentrations were adjusted using a photometer from Hanna Instruments using the N,N-diethyl-pphenylenediamine (DPD) method (test kit from Hanna Instruments). The minimum bactericidal concentration (MBC) was determined according to Gomes et al. (2018a). Three independent experiments with triplicates were performed for each condition tested.

\subsubsection{Susceptibility to antibiotics}

Antibiotics from six different classes were prepared using the solvents listed in Table 1: amoxicillin - AMO (Sigma- Aldrich, Steinheim, Germany); ciprofloxacin - CIP (Fluka, Steinheim, Germany); erythromicin - ERY (AppliChem, Darmstadt, Germany); kanamicin - KAN (Eurobio, Courtaboeuf, France); levofloxacin LEV (Alfa Aesar, Karlsruhe, Germany); oxacillin - OXA (SigmaAldrich, Steinheim, Germany); spectinomycin - SPE (SigmaAldrich, Steinheim, Germany); tetracycline - TET (Sigma-Aldrich, Steinheim, Germany); trimethoprim - sulfamethoxazole - TMPSMX (Alfa Aesar, Karlsruhe, Germany). Bacterial suspensions were adjusted to $6 \times 10^{8}$ cells $/ \mathrm{mL}$ and the disk diffusion test was applied according the Clinical and Laboratorial Standards Institute (CLSI) guidelines (CLSI, 2007) to understand the effects of CA exposure on S. maltophilia susceptibility to antibiotics. Negative controls were performed with the solvents used (DMSO, $\mathrm{NaOH}$ and $\mathrm{HCl}$ ). Three independent experiments with duplicates were performed for each condition tested.

\subsubsection{Biofilm formation ability of S. maltophilia previously exposed to $C A$}

S. maltophilia from 12 weeks biofilms was grown in R2A broth overnight at $25^{\circ} \mathrm{C}$ and $120 \mathrm{rpm}$. Then biofilms were formed according to Stepanovic et al. (2000). The cell density of each suspension was adjusted to $2 \times 10^{8}$ cells $/ \mathrm{mL}$ in R2A broth. A volume of $200 \mu \mathrm{L}$ of bacterial suspension was added to each well of a 96 -wells polystyrene (PS) microtiter plate. The plates were further incubated for $24 \mathrm{~h}$ at $25^{\circ} \mathrm{C}$ and $120 \mathrm{rpm}$. Sterile R2A broth was used as 
Table 1

Antibiotic content per disk and solvent used.

\begin{tabular}{|c|c|c|c|c|}
\hline Antibiotic & Disk content $(\mu \mathrm{g})$ & Solvent & Antibiotic class & Target \\
\hline AMO & 20 & $\mathrm{NaOH} 1 \mathrm{~N}$ & $\beta$ lactam & $\beta$ lactamase \\
\hline CIP & 5 & $\mathrm{HCl} 0.1 \mathrm{~N}$ & Fluoroquinolone & DNA topoisomerase \\
\hline ERY & 15 & DMSO & Macrolide & Protein synthesis \\
\hline KAN & 30 & Distilled water & Aminoglycoside & Protein synthesis \\
\hline LEV & 5 & DMSO & Fluoroquinolone & DNA topisomerase \\
\hline OXA & 1 & Distilled water & $\beta$-lactam & $\beta$-lactamase \\
\hline SPE & 100 & Distilled water & Aminoglycoside & Protein synthesis \\
\hline TET & 30 & DMSO & Tetracyclines & Protein synthesis \\
\hline TMP/SMX & $1.25 / 23.75$ & DMSO & Folic acid inhibitors & Folic acid \\
\hline
\end{tabular}

negative control. Biofilm production was assessed in terms of culturability (enumeration of colony forming units - CFU) and by crystal violet (Merck, Darmstadt, Germany) staining as described by Borges et al. (2017) and Gomes et al. (2018b).

\subsubsection{Chlorine effects on biofilms formed by S. maltophilia exposed to $C A$}

The 24 h-old biofilms (section 2.6.3) were treated with $130 \mathrm{mg} / \mathrm{L}$ $\mathrm{NaOCl}$ (the minimum bactericidal concentration for S. maltophilia in R2A broth) for $30 \mathrm{~min}$. Bacterial suspension from each well (section 2.6.3) was discarded and the biofilms were washed with saline water $(0.85 \% \mathrm{NaCl}-\mathrm{VWR}$, Leuven, Belgium) in order to remove non-adhered and weakly adhered cells. Afterwards, $200 \mu \mathrm{L}$ of $\mathrm{NaOCl}$ solution $(130 \mathrm{mg} / \mathrm{L}$ of free chlorine) prepared in STW was added to biofilms for $30 \mathrm{~min}$. Negative controls were obtained from exposure to $200 \mu \mathrm{L}$ of STW for $30 \mathrm{~min}$. After exposure, chlorine was removed from each well and the remaining biocide was neutralized with sodium thiosulfate at $0.50 \%$ (wt/v) for 10 min (Gomes et al., 2018a). Chlorine effects on biofilms were assessed by CFU enumeration and crystal violet staining as previously described by Borges et al. (2017) and Gomes et al. (2018b).

\subsubsection{Motility}

S. maltophilia motility was assessed after CA exposure for 12 weeks. Swimming, swarming and twitching were the three types of motility evaluated as described by Gomes et al. (2016). Briefly, bacteria isolated from CA-exposed biofilms were grown overnight in LBB (Luria-Bertani broth) and the cell density was adjusted to $5 \times 10^{6}$ cells $/ \mathrm{mL}$ in fresh LBB. A volume of $15 \mu \mathrm{L}$ of bacterial suspension was then dropped in the centre of agar plates. These agar plates were prepared with tryptone at $10 \mathrm{~g} / \mathrm{L}$ (Fisher Bioreagents, New Jersey, USA), $\mathrm{NaCl}$ at $2.5 \mathrm{~g} / \mathrm{L}$ and agar (VWR Chemicals, Leuven, Belgium) at $3 \mathrm{~g} / \mathrm{L}$ (swimming motility), $7 \mathrm{~g} / \mathrm{L}$ (swarming motility) or $15 \mathrm{~g} / \mathrm{L}$ (twitching motility). Plates were then incubated at $25^{\circ} \mathrm{C}$ for $72 \mathrm{~h}$. The colony growth was measured at $24 \mathrm{~h}$ after incubation. Three independent assays were performed with three replicates.

\subsubsection{Siderophores production}

Siderophores production was evaluated using chrome azurol S (CAS) plates prepared in R2A. Briefly, $100 \mu \mathrm{L}$ of a sterilized solution of CAS-iron dye prepared according to Schwyn and Neilands (1987) was added to $900 \mu \mathrm{L}$ R2A agar (Oxoid, Hampshire, England). A volume of $15 \mu \mathrm{L}$ of bacterial suspension adjusted to $5 \times 10^{6}$ cells $/ \mathrm{mL}$ were placed in each plate of CAS agar in three different positions. Plates were incubated for $48 \mathrm{~h}$ at $25^{\circ} \mathrm{C}$ and siderophores production was evaluated by the formation of an orange halo that was measured ( $\mathrm{mm}$ ). Three independent assays were performed with three replicates.

\subsubsection{Adhesion and internalization of $S$. maltophilia exposed to $C A$} to HT-29 cell line

Human colon adenocarcinoma cell line HT-29 (ATCC $^{\mathbb{R}}$ HTB$38^{\mathrm{TM}}$ ) (kindly provided by the Institute for Research and Innovation in Health Sciences - I3S, Porto) was selected as model to assess the potential effects from the ingestion of DW contaminated with S. maltophilia in the interaction with mammalian intestinal cells. These cells were cultured in RPMI 1640 medium (Biowester, Nuaillé - France) containing 10\% (v/v) fetal bovine serum (FBS) (Biowester, Nuaillé - France) and $1 \%(\mathrm{v} / \mathrm{v})$ antibiotics solution (Biowester, Nuaillé - France). Cultures were incubated at $37^{\circ} \mathrm{C}$ in a humidified $5 \% \mathrm{CO}_{2}$ atmosphere. HT-29 cells were seeded in 24-well plates at concentration of $4.0 \times 10^{4}$ cells per well obtaining a semiconfluent monolayers in $48 \mathrm{~h}$. Cell cultures were replenished with RPMI 1640 without antibiotics $24 \mathrm{~h}$ before the assay was performed. All cell cultures were incubated at $37^{\circ} \mathrm{C}$ in a $5 \% \mathrm{CO}_{2}$ atmosphere.

The protocol of bacterial adhesion and internalization was performed according to Gagnon et al. (2013). Briefly, S. maltophilia grown as described in section 2.1 were centrifuged at $3777 \mathrm{~g}$ for $15 \mathrm{~min}$, washed twice in saline solution $(0.85 \% \mathrm{NaCl})$. A final concentration of bacteria of $10^{6}$ per $\mathrm{mL}$ was prepared in RPMI 1640 medium. A volume of $500 \mu \mathrm{L}$ of this suspension was then added to each well of the 24-well plate containing a monolayer of HT-29. The procedure was validated with Salmonella sp. (isolated from DW), a bacterium with known ability to internalize human colon cells (Gagnon et al., 2013). Two independent assays were performed with three replicates.

2.6.7.1. S. maltophilia adhesion on HT-29 cells. To determine bacterial adhesion on HT-29, plates were incubated for $30 \mathrm{~min}$ at $37^{\circ} \mathrm{C}$ in a $2.5 \mathrm{~L}$ AnaeroJar ${ }^{\mathrm{TM}}$ with microaerophilic conditions assured by Oxoid $^{\mathrm{TM}}$ CampyGen ${ }^{\mathrm{TM}}$ sachet. Afterwards, bacterial suspension was discharged from each well and HT-29 cells were washed twice with phosphate buffered saline (PBS), in order to remove non-adhered cells. A volume of $250 \mu \mathrm{L}$ of trypsin-EDTA (Sigma-Aldrich, Steinheim, Germany) was added to each well to detach HT-29 cells and adhered bacteria. After incubation for $10 \mathrm{~min}$ at $37^{\circ} \mathrm{C}$, trypsin was inactivated by adding $250 \mu \mathrm{L}$ of RPMI 1640 with fetal bovine serum (FBS). The bottom of each well was scrapped with the pipette to guarantee the maximum removal of HT-29 monolayer. The suspension was then plated in TSA (Merck, Darmstadt, Germany) plates and incubated for $24 \mathrm{~h}$ at $37^{\circ} \mathrm{C}$ in order to assess the number of bacteria adhered on HT-29 cells.

2.6.7.2. S. maltophilia internalization in HT-29 cells. Bacteria were incubated with HT-29 cells for $90 \mathrm{~min}$ at $37^{\circ} \mathrm{C}$ in an $2.5 \mathrm{~L}$ Anaero-

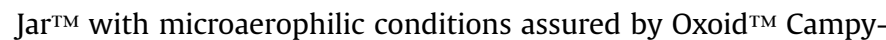
$\mathrm{Gen}^{\mathrm{TM}}$ sachet, in order to assess the ability of $S$. maltophilia to invade these cells. After incubation, the supernatant was discharged and cells were washed twice with $500 \mu \mathrm{L}$ PBS. Afterwards, $1 \mathrm{mg} / \mathrm{L}$ of levofloxacin (prepared in RPMI 1640 medium) was added to each 
well in order to kill adhered bacteria and incubated for $1 \mathrm{~h}$ (time and antibiotic concentration tested for complete inactivation of sessile S. maltophilia). Cells were washed twice with PBS after treatment with the antibiotic. A volume of $250 \mu \mathrm{L}$ of trypsin was added to each well for $10 \mathrm{~min}$, in order to detach cells from the plate (Section 2.6.4.1), followed by $250 \mu \mathrm{L}$ of ice cold Triton $\mathrm{X}-100$ (Sigma-Aldrich, Steinheim, Germany) at $2 \%(v / v)$ in order to lyse the HT-29 cells and release the internalized bacteria. The bottom of each well was scraped with a pipette to guarantee maximum cell removal. Suspensions were collected to $1.5 \mathrm{~mL}$ microtubes, vortexed and incubated for $10 \mathrm{~min}$ in order to improve homogenization and achieve complete cell lysis. The number of CFU of internalized bacteria were then assessed by plating the suspension in TSA followed by incubation for $24 \mathrm{~h}$ at $37^{\circ} \mathrm{C}$.

\subsection{Statistical analysis}

Statistical analysis of results was performed using the software IBM $^{\circledR}$ SPSS $^{\circledR}$ Statistics (Statistical Package for the Social Sciences) version 24.0. One-way analysis of variance (ANOVA) was applied and the comparisons between and within experimental groups were carried out using Tukey test. Statistical calculations were based on confidence level $\geq 95 \%(P<0.05)$ which was considered statistically significant.

\section{Results}

\subsection{Characterization of S. maltophilia from biofilms exposed to $C A$}

S. maltophilia cells were isolated from biofilms exposed to CA during 12 weeks. These cells were characterized in terms of susceptibility to chlorine (Section 3.1.1), susceptibility to nine antibiotics (AMO, CIP, ERY, KAN, LEV, OXA, SPE, TET, TMP-SMX - Section 3.1.2) using planktonic cells. Biofilm formation ability (Section 3.1.3) and susceptibility to chlorine (Section 3.1.4) were further assessed. The effects of CA were also evaluated on bacterial motility (Section 3.1.5), siderophores production (Section 3.1.6) and on the ability of $S$. maltophilia to adhere and internalize the human colon adenocarcinoma cell line HT-29.

\subsubsection{Effects of CA exposure on S. maltophilia susceptibility to chlorine}

The MBC of chlorine was used as measure of S. maltophilia susceptibility to this disinfectant. Results demonstrate that concentrations of free chlorine between 2 and $4 \mathrm{mg} / \mathrm{L}$ were bactericidal for $S$. maltophilia obtained from both biofilms grown in the presence of CA at [DW] and at $100 \times[D W]$ for 12 weeks. Significant differences were not observed between bacteria exposed to STW, DMSO and CA at $[\mathrm{DW}]$ and at $100 \times[\mathrm{DW}](P>0.05)$.

\subsubsection{Effects of CA exposure on S. maltophilia susceptibility to antibiotics}

S. maltophilia isolated from 12 weeks biofilms was resistant to AMO, OXA and SPE, regardless the conditions under which biofilms were exposed (Table 2). The exposure to CA did not alter bacterial susceptibility to these antibiotics $(P>0.05)$. S. maltophilia was susceptible to CIP, KAN, LEV, TET and TMP-SMX, when bacteria obtained from biofilms exposed to STW, DMSO and CA at [DW] and at $100 \times[\mathrm{DW}]$ were used. S. maltophilia had intermediate susceptibility to ERY. Bacteria obtained from biofilms exposed to CA at $100 \times[\mathrm{DW}]$ had higher tolerance to this antibiotic $(P<0.05)$ (Figure S.1). On the other hand, exposure to CA at $100 \times[\mathrm{DW}]$ increased susceptibility to CIP $(P<0.05)$.
Table 2

Zone of inhibition ( $\mathrm{mm}$ ) for the selected antibiotics. Mean values and the corresponding standard deviation are presented.

\begin{tabular}{lllll}
\hline Antibiotics $^{\mathrm{a}}$ & \multicolumn{4}{l}{ Halo inhibition $(\mathrm{mm})$ for each exposure condition } \\
\cline { 2 - 5 } & STW & DMSO & CA at $[\mathrm{DW}]$ & CA at $100 \times[\mathrm{DW}]$ \\
\hline AMO & $0.0 \pm 0.0$ & $0.0 \pm 0.0$ & $0.0 \pm 0.0$ & $0.0 \pm 0.0$ \\
CIP & $29.3 \pm 1.0$ & $27.0 \pm 1.4$ & $28.5 \pm 1.9$ & $31.3 \pm 1.4^{\mathrm{b}}$ \\
ERY & $19.2 \pm 2.2$ & $19.7 \pm 1.9$ & $16.6 \pm 2.7$ & $15.7 \pm 0.8^{\mathrm{b}}$ \\
KAN & $19.8 \pm 3.3$ & $22.3 \pm 2.5$ & $21.8 \pm 3.0$ & $19.0 \pm 4.8$ \\
LEV & $30.5 \pm 2.6$ & $30.7 \pm 2.8$ & $31.2 \pm 1.3$ & $30.7 \pm 1.6$ \\
OXA & $0.0 \pm 0.0$ & $0.0 \pm 0.0$ & $0.0 \pm 0.0$ & $0.0 \pm 0.0$ \\
SPE & $0.0 \pm 0.0$ & $0.0 \pm 0.0$ & $0.0 \pm 0.0$ & $0.0 \pm 0.0$ \\
TET & $14.5 \pm 2.0$ & $14.2 \pm 2.5$ & $13.7 \pm 2.0$ & $13.5 \pm 1.8$ \\
TMP - SMX & $28.3 \pm 1.2$ & $28.3 \pm 0.8$ & $28.3 \pm 1.0$ & $28.2 \pm 1.3$ \\
\hline
\end{tabular}

a AMO- amoxicillin, CIP- ciprofloxacin, ERY - erythromycin, KAN- kanamycin, LEV - levofloxacin, OXA - oxacylin, SPE- Spectinomycin, TET - tetracycline, TMP SMX - trimethoprim-sulfamethoxazole.

$\mathrm{b}$ Zone of inhibition statistically different from those obtained after exposure to the solvent (DMSO) $-P<0.05$.

\subsubsection{Effects of CA exposure on S. maltophilia biofilm formation and susceptibility to chlorine}

S. maltophilia from CA-exposed biofilms were used to assess their ability to form biofilms and the susceptibility of these biofilms to chlorine in terms of total biomass (crystal violet method - Fig. 1) and culturability $\left(\log \mathrm{CFU} / \mathrm{cm}^{2}-\right.$ Fig. 2). It was found that exposure to $1 \%$ DMSO (solvent control) for 12 weeks increased S. maltophilia ability to form biofilms on PS compared to $S$. maltophilia exposed to STW for 12 weeks $(P<0.05)$. However, exposure to CA at [DW] and $100 \times[D W]$ did not cause significant changes in biofilm formation
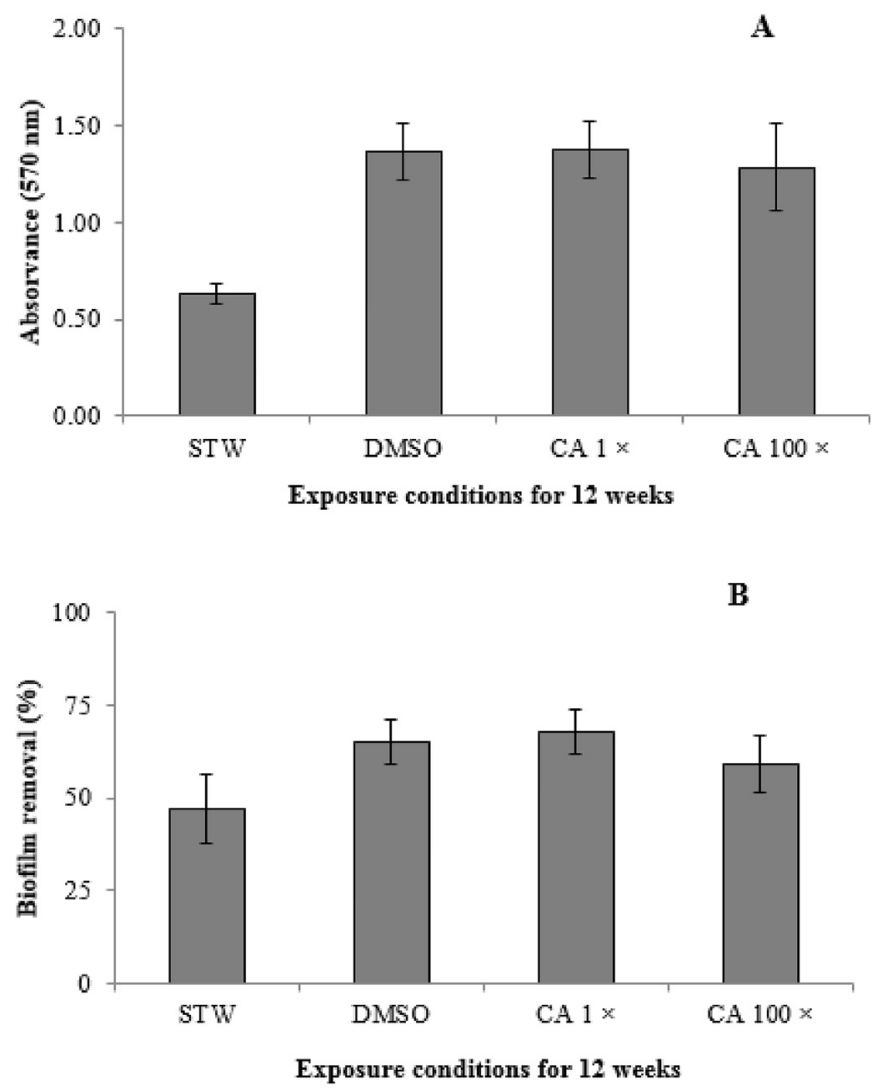

Fig. 1. Biofilm formation for $24 \mathrm{~h}$ after S. maltophilia exposure to STW, DMSO and CA at [DW] and $100 \times[\mathrm{DW}]$ for 12 weeks in terms of total biomass as assessed by crystal violet staining (absorvance at $570 \mathrm{~nm}$ ) - A. Biofilm removal after treatment with free chlorine $(130 \mathrm{mg} / \mathrm{L})$ for $30 \mathrm{~min}$ in terms of total biomass $-\mathrm{B}$. 


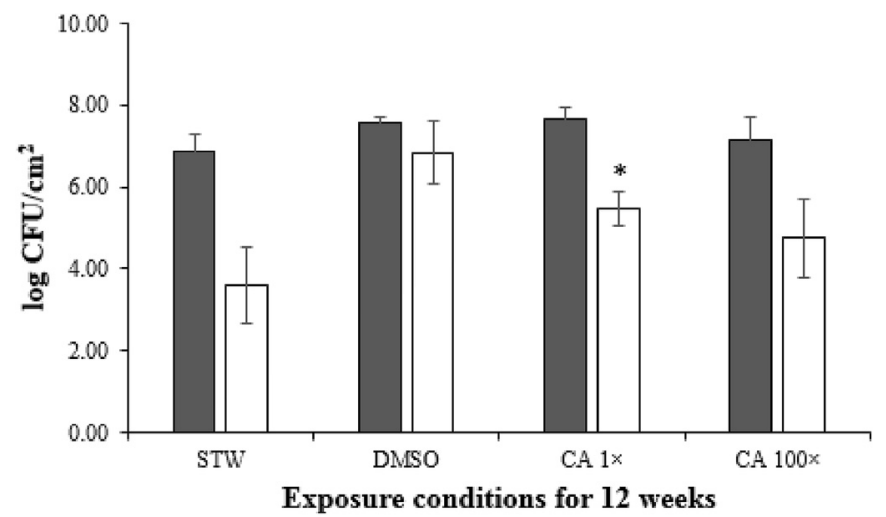

Fig. 2. The effects of the exposure to STW, DMSO at $1 \%, C A$ at [DW] and $100 \times[D W]$ for 12 weeks on the ability of $S$. maltophilia to form biofilms, with data presented as log $\mathrm{CFU} / \mathrm{cm}^{2}$ ( $)$. Biofilm susceptibility to free chlorine at $130 \mathrm{mg} / \mathrm{L}$ for $30 \mathrm{~min}$, with data presented as $\log \mathrm{CFU} / \mathrm{cm}^{2}$ reduction $(\square)$.* $^{*}$ - mean values statistically different from those obtained after exposure to the solvent (DMSO) $-P<0.05$.

when compared to the solvent control $(P>0.05)$ (Fig. 1.A).

Complete biofilm removal was not obtained after treatment with $130 \mathrm{mg} / \mathrm{L}$ of free chlorine for $30 \mathrm{~min}$ (Fig. 1.B). Biofilms formed after exposure to DMSO were removed in a higher extent $(65 \%$ biofilm removal) than biofilms formed after exposure to STW (47\% biofilm removal). S. maltophilia exposed to CA at [DW] formed biofilms with similar susceptibility to these obtained from S. maltophilia exposed to DMSO $(P>0.05)$. Although, statistically significant differences were not observed, the biofilms formed after S. maltophilia exposure to CA at $100 \times[\mathrm{DW}]$ showed a decrease in removal from chlorine exposure.

The culturability of S. maltophilia biofilms was not significantly affected by the conditions under which the cells were grown, i.e. exposed to CA at [DW], $100 \times[\mathrm{DW}]$ and solvent control (DMSO at $1 \%)(P>0.05)$. A slight increase in CFU numbers was observed for biofilms exposed to DMSO (1\%) in comparison to those formed after exposure to STW for 12 weeks $(P<0.05)$. Complete CFU reduction was not achieved after $30 \mathrm{~min}$ in the presence of $130 \mathrm{mg} / \mathrm{L}$ of free chlorine for any of the biofilms tested. However, reductions of 3.60, 6.84, 5.48 and $4.76 \log \mathrm{CFU} / \mathrm{cm}^{2}$ were obtained for biofilms formed after S. maltophilia exposure to STW, DMSO, CA at [DW] and at $100 \times[D W]$, respectively. This means that CFU reduction decreased significantly due to previous bacterial exposure to CA compared to the DMSO control $(P<0.05)$. Moreover, increasing the levels of CA exposure decreased $\mathrm{CFU}$ reduction, even if not statistically significant $(P>0.05)$.

\subsubsection{Effects of CA exposure on S. maltophilia motility}

The exposure to CA at both concentrations tested did not cause significant changes (Table 3 ) in S. maltophilia swimming and twitching motilities $(P>0.05)$. The previous exposure to CA at [DW] slightly increased $S$. maltophilia swarming motility, even if not

Table 3

Motility of S. maltophilia from biofilms grown in the presence of CA at [DW], $100 \times$ [DW], DMSO and STW. Motility halos were measured $24 \mathrm{~h}$ after incubation. Diameter of the initial drop was $7.2 \pm 0.4 \mathrm{~mm}$.

\begin{tabular}{llll}
\hline \multirow{2}{*}{ Condition } & \multicolumn{3}{l}{ Colony growth halo $(\mathrm{mm})$} \\
\cline { 2 - 4 } & Swimming & Swarming & Twitching \\
\hline STW & $11.0 \pm 0.1$ & $8.6 \pm 0.5$ & $10.9 \pm 0.6$ \\
DMSO & $8.0 \pm 0.0$ & $8.5 \pm 0.0$ & $9.8 \pm 0.8$ \\
CA [DW] & $8.1 \pm 0.3$ & $8.9 \pm 0.1$ & $9.3 \pm 0.1$ \\
CA $100 \times[\mathrm{DW}]$ & $8.3 \pm 0.8$ & $8.6 \pm 0.6$ & $10.0 \pm 0.9$ \\
\hline
\end{tabular}

statistically significant $(P>0.05)$.

\subsubsection{Effects of CA exposure on S. maltophilia siderophores production}

S. maltophilia was found to be able to produce siderophores for iron acquision when this metal is limiting in the environment (Table 4). The results further demonstrate that the diameter of the orange halo formed around the growing colony was very similar for all the CA-exposed cells and the control $(P>0.05)$.

\subsubsection{Effects of CA exposure on S. maltophilia ability to adhere and internalize within HT-29 cells}

S. maltophilia demonstrated to be able to adhere and internalize HT-29 cells (Fig. 3). The exposure to CA did not affect the ability of S. maltophilia to adhere on HT-29 cells. For both CA concentrations 5.19-5.29 $\log$ CFU of $S$. maltophilia was able to adhere $(P>0.05)$. Following adhesion, S. maltophilia was able to invade HT-29 cells. However, internalization was significantly lower for S. maltophilia obtained from CA-exposed biofilms $(P<0.05)$ (Fig. 3).

\section{Discussion}

The effects of the presence of CA on S. maltophilia tolerance to chlorine and antibiotics were evaluated under conditions mimicking DWDS. Also, the effects on bacterial virulence factors, such as biofilm formation, motility, siderophores production as well as adhesion and invasion of human colon carcinoma cells were assessed. S. maltophilia is an emerging pathogen characterized as a multi-drug resistant and often detected in tap water (Cervia et al., 2008; Amoli et al., 2017a, 2017b). Therefore, following the One Health initiative, it is of utmost importance to understand how ECs may affect bacterial behavior and the potential impacts from such behavioral changes for public health.

CA is a metabolite of clofibrate, etofibrate, and etofyllinclofibrate, pharmaceuticals commonly used as lipid regulators (Stumpf

Table 4

Siderophores production after exposure to CA. Diameter of the orange halo around the grown colony $(\mathrm{mm})$.

\begin{tabular}{lc}
\hline Condition & Siderophores production halo $(\mathrm{mm})$ \\
\hline STW & $1.6 \pm 0.3$ \\
DMSO & $1.6 \pm 0.6$ \\
CA [DW] & $1.4 \pm 0.4$ \\
CA $100 \times[\mathrm{DW}]$ & $1.4 \pm 0.1$ \\
\hline
\end{tabular}

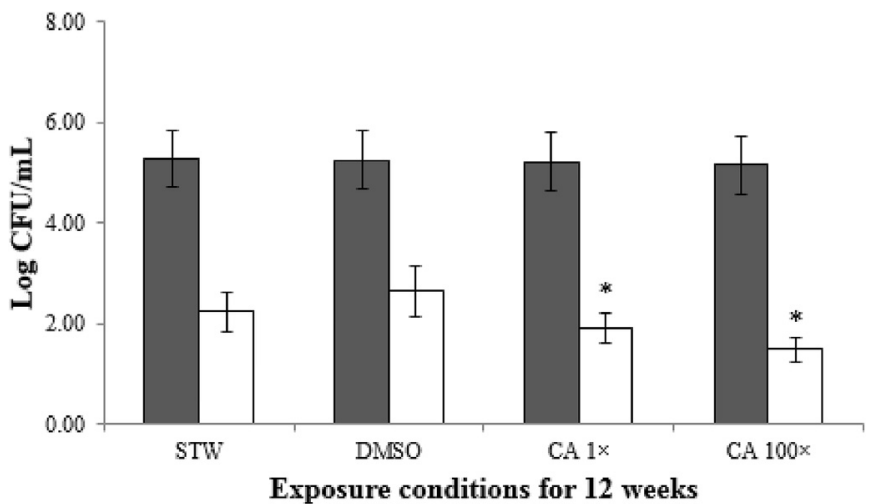

Fig. 3. Effects of CA exposure on S. maltophilia interaction with HT - 29 cells. $\square$ S. maltophilia adhesion on HT-29 cells; $\square$-S. maltophilia internalization in HT-29 cells. * - mean values statistically different from those obtained after the exposure to the solvent (DMSO) $-P<0.05$. 
et al., 1999). CA is also an isomer of the herbicide mecoprop (Buser et al., 1998) and was the first pharmaceutical detected in the environment as contaminant (Evangelista et al., 2010). Although it has been discontinued as pharmaceutical and new drugs have been used to replace it, this molecule is still a concern, due to its widespread occurrence and its environmental persistence (Emblidge and DeLorenzo, 2006). CA was selected for this study based on previous results (Gomes et al., 2018a) on ECs effect on bacteria, where CA was found to be present in all the combinations of ECs causing changes in bacterial behavior. For instance, S. maltophilia exposure to CA at $1700 \mathrm{ng} / \mathrm{L}$ or to the combination of CA $(170 \mathrm{ng} / \mathrm{L})$ and ibuprofen - IBP ( $3 \mathrm{ng} / \mathrm{L}$ ) increased biofilm formation ability. On the other hand the exposure to the combination of CA (1700 ng/L) with carbamazepine (CBZ at $2580 \mathrm{ng} / \mathrm{L}$ ) and IBP (30 ng/L) reduced biofilm productivity (Gomes et al., 2018a). The biofilms formed after exposure to the combination of CA (170 ng/L) and CBZ (258 ng/ $\mathrm{L})$ or CA (1700 ng/L), CBZ (2580 ng/L) and IBP (30 ng/L) were also more tolerant to disinfection with chlorine (Gomes et al., 2018b). Based on these results (Gomes et al., 2018a) and on CA environmental persistence (Schmidt et al., 2017), this EC was selected for the present study.

The tolerance of planktonic S. maltophilia to free chlorine was not affected from CA exposure. Concentrations of free chlorine, 2-4 mg/L, slightly higher than those recommended for chlorinated DWDS (0.5-1 mg/L) (WHO, 2011) were needed to cause bactericidal effects. Therefore, $S$. maltophilia may be able to survive in chlorinated systems, and other works already described the presence of S. maltophilia in chlorinated DWDS (Silbaq, 2009; Amoli et al., 2017a). The use of chlorine is a widespread strategy used to avoid bacterial growth along DWDS. However, it is not completely efficient and the presence of ARBs has been consistently reported (Xi et al., 2009; Li and Gu, 2018). The use of sub-inhibitory concentrations of disinfectants is known to be responsible for the increase of incidence of ARBs and ARGs in DWDS (Li and Gu, 2018). Previous studies propose that the presence of antibiotic residues in the environment are responsible for the selection and spread of ARBs and ARGs (Baquero et al., 2008; Martinez, 2009; Xie et al., 2019). However, information on the effects of non-antibiotic contaminants on bacterial resistance to antimicrobials is scarce. Subirats et al. (2017) studied the effects of contaminated wastewater on the resistome of biofilms. Using a variety of contaminants they found that biofilms exposed to wastewater had higher levels of ARBs and ARGs than biofilms exposed to treated wastewater. Wang et al. (2019) also verified that exposure to ciprofloxacin and sulfadiazine promoted ARGs spread in drinking water biofilms. The present results demonstrated that $S$. maltophilia was resistant to AMO, OXA and SPE, even without being exposed to CA (Table 2). S. maltophilia is commonly described as an opportunistic pathogen with intrinsic multidrug-resistance (Zhang et al., 2000; Sánchez, 2015; Adegoke et al., 2017; Rizek et al., 2018). However, it is also known that S. maltophilia can acquire resistance (Song et al., 2010; Furlan et al., 2018; Rizek et al., 2018). This study demonstrates that exposure to $\mathrm{CA}$ at $100 \times$ [DW] increased $S$. maltophilia tolerance to ERY (Table 2, Figure S.1). Some works described that S. maltophilia strains may use efflux pump systems to pump out ERY such as the SmDEF, SmeOP, EmrCABsm and MexCD-OprJ, and in some cases the influx of this antibiotic through the bacterial membrane is not favored due to the reduced permeability of the outer membrane (Alonso et al., 2000; Safdar and Rolston, 2007; Chang et al., 2015; Adegoke et al., 2017). It is possible CA exposure may increase the activity of some $S$. maltophilia efflux systems or alter bacteria membrane permeability, therefore increase tolerance to ERY. Balagué and Véscovi (2001) demonstrated that exposure to CA, ethacrynic acid (EA) and 2,4-dichlorophenoxyacetic acid (2,4-D) altered the outer membrane permeability of Escherichia coli. E. coli exposure to these aryloxoalcanoic agents - CA, EA and 2,4-D caused the induction of the MarAB regulatory system (Balagué and Véscovi, 2001). Balagué et al. (2006) further studied the effects from exposure of $E$. coli to CA, EA and 2,4-D (three structurally analogue compounds) on ERY susceptibility. No significant effects from CA exposure were observed on the antibiotic action of ERY. On the other hand, E. coli was more tolerant to ERY when exposed to the other two CA analogs. It is important to emphasize that the concentrations used in that study are the therapeutic doses (CA $28.6 \mathrm{mg} / \mathrm{kg} / \mathrm{d}, \mathrm{EA}-2.9 \mathrm{mg} / \mathrm{kg} / \mathrm{d}$ and 2,4-D - $70 \mathrm{mg} / \mathrm{kg} / \mathrm{d}$ ) which are significantly higher than the trace concentrations detected in environment (170-17000 ng/L). TMP-SMX is the most common therapeutic option used to treat S. maltophilia infections (Emblidge and DeLorenzo, 2006; Sánchez and Martínez, 2015) and tolerance to this combination of antibiotics was not observed despite the exposure of $S$. maltophilia to CA.

CA had no remarkable effects on S. maltophilia ability to form biofilms. Significant changes in biofilm formation ability were observed after exposure to DMSO, particularly the increase in biofilm formation. Lim et al. (2012) also observed an increase in E. coli biofilm formation after exposure to $4 \%$ DMSO. This emphasizes the importance of adequate control testing for a reliable analysis of results. Biofilms formed by $S$. maltophilia exposed to CA were more tolerant to chlorine action (Fig. 2). The changes in biofilm tolerance to chlorine were mostly in bacterial inactivation (Fig. 2), and not in biofilm removal (Fig. 1). This altered tolerance can result from changes on the bacterial membrane structure or associated proteins caused by the prolonged exposure to CA, as proposed by Balagué et al. (2006). Therefore, it is important to take into account that prolonged exposure of DW bacteria to CA may hinder DW disinfection with chlorine. For a shorter exposure to CA (26 d), Gomes et al. (2018a) did not observe changes in biofilm susceptibility to chlorine.

Siderophores are molecules produced by microorganisms whose main function is to chelate the ferric iron $\left(\mathrm{Fe}^{3+}\right)$ from different environments making it available for the producer microorganism. Siderophores production is considered a virulence factor as during the infectious process microbes secrete siderophores to acquire and solubilize ferric iron from the host (Wilson et al., 2016). Iron is essential to host cells, being regulated by iron transport systems. Nevertheless, the affinity of bacterial siderophores to iron are generally much higher than those of host proteins/molecules, allowing pathogens to outcompete the host in iron acquisition (Wilson et al., 2016). This study shows that S. maltophilia produces siderophores regardless the conditions tested. Nas and Cianciotto (2017) also described the production of siderophores by $S$. maltophilia, suggesting a unique siderophore structure for iron acquisition for this species. However, no changes in siderophores production were observed from CA exposure (Table 4).

S. maltophilia motility was also studied in the present work as it is an important factor affecting bacterial ability to form biofilms as well as the interaction with host cells (Trifonova and Strateva, 2018). In pathogens, motility and virulence are often linked by a complex regulatory system (Josenhans and Suerbaum, 2002). It is known that the ability of $S$. maltophilia to adhere on host tissues and infect host cells is related to motility (Adegoke et al., 2017; Trifonova and Strateva, 2018). Swimming motility is usually related to the ability of bacteria to move in liquid medium due to the presence of functional flagella (Ha et al., 2014). Swarming is related to the flagellum-mediated movement of bacteria, responsible for biofilm spread over a surface (Vanderleyden et al., 2004). In this study, the modest increase in swarming motility caused by CA did not cause changes in biofilm formation. Twitching motility is mediated by type IV pilli, a polar fimbriae responsible for bacterial 
adhesion on eukaryotic cells and abiotic surfaces, also allowing its movement over surfaces (Deziel et al., 2001). The presence of fimbriae is a virulence factor described for S. maltophilia - essential for colonization of the host and crucial in the infection process (Trifonova and Strateva, 2018). The results demonstrated no significant changes in bacterial twitching motility after CA exposure (Table 3). Therefore, it is possible to predict that S. maltophilia adhesion on intestinal cells may not be influenced by CA exposure. In fact, the results corroborate this prediction and no significant effect was observed on the ability of CA exposed S. maltophilia to adhere on HT-29 cells (Fig. 3). CA exposure slightly decreased S. maltophilia ability to internalize within HT-29 cells. This can be attributed to changes in S. maltophilia invasion mechanisms caused by CA. Two mechanisms of bacterial invasion of hosts cells are recognized: the zipper mechanism of cell invasion (outer membrane proteins of bacteria will interact with the host membrane and force the cytoskeletal rearrangement for invasion); the trigger mechanism (is a consequence of the production of effectors that will rearrange the host cytoskeletal structure enabling invasion) (Ribet and Cossart, 2015). Balagué et al. (2004) observed that CA was responsible for a decrease in the expression of membrane proteins and fimbriae in E. coli, with significant impact on bacterial ability to invade host cells.

\section{Conclusions}

The presence of ECs in DW is a problem of potential environmental and public health concern. Their impacts on the DW microbiome and as drivers affecting resistance evolution/selection is far from being understood. This is particularly critical for nonantibiotic drugs. The present work showed that the presence of trace concentrations of CA did not affect planktonic S. maltophilia tolerance to chlorine. Nevertheless, the presence of CA in DW was responsible for the formation of biofilms with higher tolerance to chlorine disinfection. S. maltophilia ability to produce virulence factors and the ability to form biofilms was also not altered from CA exposure. Of additional concern was the changes observed in S. maltophilia susceptibility to antibiotics. After exposure to CA at $17000 \mathrm{ng} / \mathrm{L}$ S. maltophilia was more tolerant to ERY. Moreover, changes were observed on the ability of $S$. maltophilia to internalize within HT-29 cells. In general, the results propose that CA influenced $S$. maltophilia behavior. It is important to highlight that CA exposure was carried out for 12 weeks. It is expected that real environmental conditions where accumulation and exposure periods higher than 12 weeks can occur will increase the impact of CA on S. maltophilia planktonic and biofilm behavior.

\section{Fundings}

This work was financially supported by: project UID/EQU/ 00511/2019 - Laboratory for Process Engineering, Environment, Biotechnology and Energy - LEPABE funded by national funds through FCT/MCTES (PIDDAC); Projects POCI-01-0145-FEDER030219, POCI-01-0145-FEDER-028397 and POCI-01-0247-FEDER035234 funded by FEDER funds through COMPETE2020 - Programa Operacional Competitividade e Internacionalização (POCI) and by national funds (PIDDAC) through FCT/MCTES; Project "LEPABE-2-ECO-INNOVATION" - NORTE-01-0145-FEDER-000005, funded by Norte Portugal Regional Operational Programme (NORTE, 2020), under PORTUGAL 2020 Partnership Agreement, through the European Regional Development Fund (ERDF). Grants attributed by Portuguese Foundation for Science and Technology FCT - to Inês Gomes (SFRH/BD/103810/2014) and to Micaela Machado Querido (SFRH/BD/130203/2017).

Authors declare no conflict of interests.

\section{Appendix A. Supplementary data}

Supplementary data to this article can be found online at https://doi.org/10.1016/j.chemosphere.2019.06.184.

\section{References}

Abberton, C.L., Bereschenko, L., van der Wielen, P.W.J.J., Smith, C.J., 2016. Survival, biofilm formation, and growth potential of environmental and enteric Escherichia coli strains in drinking water microcosms. Appl. Environ. Microbiol. 82, 5320

Abe, Y., Skali-Lami, S., Block, J.-C., Francius, G., 2012. Cohesiveness and hydrodynamic properties of young drinking water biofilms. Water Res. 46, 1155-1166.

Adegoke, A.A., Stenström, T.A., Okoh, A.I., 2017. Stenotrophomonas maltophilia as an emerging ubiquitous pathogen: looking beyond contemporary antibiotic therapy. Front. Microbiol. 8, 2276-2276.

Alonso, A. Sanchez, P. Martínez, J.L, 2000, Stenotrophomonas maltophilia D457R contains a cluster of cenes from gram-positive bacteria involved in antibiotic and heavy metal resistance. Antimicrob. Agents Chemother. 44, 1778.

Amoli, R.I., Nowroozi, J., Sabokbar, A., Fattahi, S., Amirbozorgi, G., 2017a. Isolation of Stenotrophomonas maltophilia from water and water tap. Biomed. Res. 28, 8750-8754.

Amoli, R.I., Nowroozi, J., Sabokbar, A., Rajabniya, R., 2017b. Isolation of Stenotrophomonas maltophilia from clinical samples: an investigation of patterns motility and production of melanin pigment. Asian Pac. J. Trop. Biomed. 7, $826-830$

Balagué, C., Sturtz, N., Rey, R., De Ruiz, C.S., Nader-Macias, M.E., Duffard, R., De Duffard, A.M., 2006. Aryloxoalcanoic compounds induce resistance to antibiotic therapy in urinary tract infection caused by Escherichia coli. FEMS Immunol. Med. Microbiol. 48, 337-346.

Balagué, C., Véscovi, E.G., 2001. Activation of multiple antibiotic resistance in uropathogenic Escherichia coli strains by aryloxoalcanoic acid compounds. Antimicrob. Agents Chemother. 45, 1815-1822.

Balagué, C.E., de Ruiz, C.S., Rey, R., de Duffard, A.M., Nader-Macias, M.E., 2004 Clofibric and ethacrynic acids prevent experimental pyelonephritis by Escherichia coli in mice. FEMS Immunol. Med. Microbiol. 42, 313-319.

Baquero, F., Martínez, J.-L., Cantón, R., 2008. Antibiotics and antibiotic resistance in water environments. Curr. Opin. Biotechnol. 19, 260-265.

Borges, A., Lopez-Romero, J.C., Oliveira, D., Giaouris, E., Simões, M., 2017. Prevention, removal and inactivation of Escherichia coli and Staphylococcus aureus biofilms using selected monoterpenes of essential oils. J. Appl. Microbiol. 123, 104-115.

Buser, H.-R., Müller, M.D., Theobald, N., 1998. Occurrence of the pharmaceutical drug clofibric acid and the herbicide mecoprop in various swiss lakes and in the North Sea. Environ. Sci. Technol. 32, 188-192.

Cervia, J.S., Ortolano, G.A., Canonica, F.P., 2008. Hospital tap water as a source of Stenotrophomonas maltophilia infection. Clin. Infect. Dis. 46, 1485-1487.

Chang, Y.-T., Lin, C.-Y., Chen, Y.-H., Hsueh, P.-R., 2015. Update on infections caused by Stenotrophomonas maltophilia with particular attention to resistance mechanisms and therapeutic options. Front. Microbiol. 6, 893-893.

CLSI, 2007. Performance Standard for Antimicrobial Susceptibility Testing. In: Seventeenth Informational Supplement. Institute CaLS, Pennsylvania, USA

Delgado-Moreno, L., Bazhari, S., Nogales, R., Romero, E., 2019. Innovative application of biobed bioremediation systems to remove emerging contaminants: adsorption, degradation and bioaccesibility. Sci. Total Environ. 651, 990-997.

Deziel, E., Comeau, Y., Villemur, R., 2001. Initiation of biofilm formation by Pseudomonas aeruginosa 57RP correlates with emergence of hyperpiliated and highly adherent phenotypic variants deficient in swimming, swarming, and twitching motilities. J. Bacteriol. 183, 1195-1204.

Emblidge, J.P., DeLorenzo, M.E., 2006. Preliminary risk assessment of the lipidregulating pharmaceutical clofibric acid, for three estuarine species. Environ. Res. 100, 216-226.

EPA, 2011. Development and Testing of Methods to Decontaminate a Building's Plumbing System Impacted by a Water Contamination Event: Decontamination of Bacillus Spores. United States Environmental Protection Agency, USA.

Evangelista, S., Cooper, D.G., Yargeau, V., 2010. The effect of structure and a secondary carbon source on the microbial degradation of chlorophenoxy acids. Chemosphere 79, 1084-1088.

Furlan, J.P.R., Sanchez, D.G., Gallo, I.F.L., Stehling, E.G., 2018. Characterization of acquired antimicrobial resistance genes in environmental Stenotrophomonas maltophilia isolates from Brazil. Microb. Drug Resist. (Larchmont, N.Y.).

Gabarrón, S., Gernjak, W., Valero, F., Barceló, A., Petrovic, M., Rodríguez-Roda, I. 2016. Evaluation of emerging contaminants in a drinking water treatment plant using electrodialysis reversal technology. J. Hazard Mater. 309, 192-201.

Gagnon, M., Zihler Berner, A., Chervet, N., Chassard, C., Lacroix, C., 2013. Comparison of the Caco-2, HT-29 and the mucus-secreting HT29-MTX intestinal cell models to investigate Salmonella adhesion and invasion. J. Microbiol. Methods 94 274-279.

Geissen, V., Mol, H., Klumpp, E., Umlauf, G., Nadal, M., van der Ploeg, M., van de Zee, S.E.A.T.M., Ritsema, C.J., 2015. Emerging pollutants in the environment: a challenge for water resource management. Int. Soil Water Conserv. Res. 3, 57-65.

Gibbs, E.P.J., 2014. The evolution of One Health: a decade of progress and challenges for the future. Vet. Rec. 174, 85 
Gomes, I.B., Simões, L.C., Simões, M., 2018a. The effects of emerging environmenta contaminants on Stenotrophomonas maltophilia isolated from drinking water in planktonic and sessile states. Sci. Total Environ. 643, 1348-1356.

Gomes, I.B., Madureira, D., Simões, L.C., Simões, M., 2018b. The effects of pharmaceutical and personal care products on the behavior of Burkholderia cepacia isolated from drinking water. Int. Biodeterior. Biodegrad.

Gomes, I.B., Simões, M., Simões, L.C., 2016. The effects of sodium hypochlorite against selected drinking water-isolated bacteria in planktonic and sessile states. Sci. Total Environ. 565, 40-48.

Guyot, A., Turton, J.F., Garner, D., 2013. Outbreak of Stenotrophomonas maltophilia on an intensive care unit. J. Hosp. Infect. 85, 303-307.

Ha, D.G., Kuchma, S.L., O'Toole, G.A., 2014. Plate-based assay for swimming motility in Pseudomonas aeruginosa. Methods Mol. Biol. 1149, 59-65.

Heberer, T., Stan, H.J., 1997. Determination of clofibric acid and N-(Phenylsulfonyl)Sarcosine in sewage, river and drinking water AU - heberer, Th. Int. J. Environ. Anal. Chem. 67, 113-124.

Huber, M.M., GÖbel, A., Joss, A., Hermann, N., LÖffler, D., McArdell, C.S., Ried, A. Siegrist, H., Ternes, T.A., von Gunten, U., 2005. Oxidation of pharmaceuticals during ozonation of municipal wastewater effluents: a pilot study. Environ. Sci. Technol. 39, 4290-4299.

Jones, O.A., Lester, J.N., Voulvoulis, N., 2005. Pharmaceuticals: a threat to drinking water? Trends Biotechnol. 23, 163-167.

Josenhans, C., Suerbaum, S., 2002. The role of motility as a virulence factor in bacteria. Int. J. Med. Microbiol. 291, 605-614.

Jux, U., Baginski, R.M., Arnold, H.-G., Krönke, M., Seng, P.N., 2002. Detection of pharmaceutical contaminations of river, pond, and tap water from Cologne (Germany) and surroundings. Int. J. Hyg Environ. Health 205, 393-398.

Kim, H.Y., Lee, I.S., Oh, J.E., 2017. Human and veterinary pharmaceuticals in the marine environment including fish farms in Korea. Sci. Total Environ. 579 $940-949$.

Kummerer, K., 2001. Introduction: pharmaceutical in the environment. In: Kummer, K. (Ed.), Pharmaceutical in the Environment: Sources, Fate, Effects and Risks. Springer-Verlag Berlin Heidelberg, New York, USA, p. 5.

Li, D., Gu, A.Z., 2018. Antimicrobial resistance: a new threat from disinfection byproducts and disinfection of drinking water? Curr. Opin. Environ. Sci. Health.

Lim, J.Y., May, J.M., Cegelski, L., 2012. Dimethyl sulfoxide and ethanol elicit increased amyloid biogensis and amyloid-integrated biofilm formation in Escherichia coli. App. Environ. Microbiol. 78, 3369-3378.

Martinez, J.L., 2009. Environmental pollution by antibiotics and by antibiotic resistance determinants. Environ. Pollut. 157, 2893-2902.

Matamoros, V., Rodríguez, Y., Albaigés, J., 2016. A comparative assessment of intensive and extensive wastewater treatment technologies for removing emerging contaminants in small communities. Water Res. 88, 777-785.

Nas, M.Y., Cianciotto, N.P., 2017. Stenotrophomonas maltophilia produces an EntC dependent catecholate siderophore that is distinct from enterobactin. Microbiology (Read.) 163, 1590-1603.

Nega, M., Braun, B., Künzel, S., Szewzyk, U., 2019. Evaluating the impact ofwastewater effluent on microbial communities in the Panke, an Urban River. Wate 11. Switzerland.

Ortolano, G.A., Cervia, J.S., Canonica, F.P., 2008. Hospital tap water as a source of Stenotrophomonas maltophilia infection. Clin. Infect. Dis. 46, 1485-1487.

Petropavlovskii, A., Sillanpää, M., 2013. Removal of micropollutants by biofilms: current approaches and future prospects AU - petropavlovskii, Aleksei. Environ. Technol. Rev. 2, 29-44.

Pojana, G., Fantinati, A., Marcomini, A., 2011. Occurrence of environmentally relevant pharmaceuticals in Italian drinking water treatment plants AU - pojana, Giulio. Int. J. Environ. Anal. Chem. 91, 537-552.

Prest, E.I., Hammes, F., van Loosdrecht, M.C.M., Vrouwenvelder, J.S., 2016. Biologica stability of drinking water: controlling factors, methods, and challenges. Front. Microbiol. 7, 45-45.

Ribet, D., Cossart, P., 2015. How bacterial pathogens colonize their hosts and invade deeper tissues. Microb. Infect. 17, 173-183.

Rigobello, E.S., Dantas, A.D.B., Di Bernardo, L., Vieira, E.M., 2013. Removal of diclofenac by conventional drinking water treatment processes and granular activated carbon filtration. Chemosphere 92, 184-191.

Rizek, C.F., Jonas, D., Garcia Paez, J.I., Rosa, J.F., Perdigão Neto, L.V., Martins, R.R., Moreno, L.Z., Rossi Junior, A., Levin, A.S., Costa, S.F., 2018. Multidrug-resistant Stenotrophomonas maltophilia: description of new MLST profiles and resistance and virulence genes using whole-genome sequencing. J. Glob. Antimicrob. Resist. 15, 212-214.

Rizzo, L., Malato, S., Antakyali, D., Beretsou, V.G., Đolić, M.B., Gernjak, W., Heath, E. vancev-Tumbas, I., Karaolia, P., Lado Ribeiro, A.R., Mascolo, G., McArdell, C.S., Schaar, H., Silva, A.M.T., Fatta-Kassinos, D., 2019. Consolidated vs new advanced treatment methods for the removal of contaminants of emerging concern from urban wastewater. Sci. Total Environ. 655, 986-1008.

Safdar, A., Rolston, K.V., 2007. Stenotrophomonas maltophilia: changing spectrum of a serious bacterial pathogen in patients with cancer. Clin. Infect. Dis. 45 , 1602-1609.

Sánchez, M.B., 2015. Antibiotic resistance in the opportunistic pathogen Stenotrophomonas maltophilia. Front. Microbiol. 6, 658-658.

Sánchez, M.B., Martínez, J.L., 2015. The efflux pump SmeDEF contributes to trimethoprim-sulfamethoxazole resistance in Stenotrophomonas maltophilia. Antimicrob. Agents Chemother. 59, 4347.

Schmidt, N., Page, D., Tiehm, A., 2017. Biodegradation of pharmaceuticals and endocrine disruptors with oxygen, nitrate, manganese (IV), iron (III) and sulfate as electron acceptors. J. Contam. Hydrol. 203, 62-69.

Schwyn, B., Neilands, J.B., 1987. Universal chemical assay for the detection and determination of siderophores. Anal. Biochem. 160, 47-56.

Shih, H.-Y., Lin, Y.E., 2010. Efficacy of copper-silver ionization in controlling biofilmand plankton-associated waterborne pathogens. Appl. Environ. Microbiol. 76, 2032.

Silbaq, F.S., 2009. Viable ultramicrocells in drinking water. J. Appl. Microbiol. 106, 106-117.

Simões, L.C., Simões, M., 2013. Biofilms in drinking water: problems and solutions. RSC Adv. 3, 2520-2533.

Simões, L.C., Simões, M., Oliveira, R., Vieira, M.J., 2007. Potential of the adhesion of bacteria isolated from drinking water to materials. J. Basic Microbiol. 47, 174-183.

Smith, K.M., Machalaba, C.C., Seifman, R., Feferholtz, Y., Karesh, W.B., 2019. Infectious Disease and Economics: the Case for Considering Multi-Sectoral Impacts, vol. 7. One health, Amsterdam, Netherlands, 100080-100080.

Song, J.H., Sung, J.Y., Kwon, K.C., Park, J.W., Cho, H.H., Shin, S.Y., Ko, Y.H., Kim, J.M., Shin, K.S., Koo, S.H., 2010. Analysis of acquired resistance genes in Stenotrophomonas maltophilia. Korean J. Lab. Med. 30, 295-300.

Stepanovic, S., Vukovic, D., Dakic, I., Savic, B., Svabic-Vlahovic, M., 2000. A modified microtiter-plate test for quantification of staphylococcal biofilm formation. J. Microbiol. Methods 40, 175-179.

Stumpf, M., Ternes, T.A., Wilken, R.-D., Silvana Vianna, R., Baumann, W., 1999. Polar drug residues in sewage and natural waters in the state of Rio de Janeiro, Brazil. Sci. Total Environ. 225, 135-141.

Subirats, J., Triadó-Margarit, X., Mandaric, L., Acuña, V., Balcázar, J.L., Sabater, S., Borrego, C.M., 2017. Wastewater pollution differently affects the antibiotic resistance gene pool and biofilm bacterial communities across streambed compartments. Mol. Ecol. 26, 5567-5581.

Torresi, E., Polesel, F., Bester, K., Christensson, M., Smets, B.F., Trapp, S. Andersen, H.R., Plosz, B.G., 2017. Diffusion and sorption of organic micropollutants in biofilms with varying thicknesses. Water Res. 123, 388-400.

Trifonova, A., Strateva, T., 2018. Stenotrophomonas maltophilia - a low-grade pathogen with numerous virulence factors AU - Trifonova, Angelina. Infect. Dis. 1-11.

Tröger, R., Klöckner, P., Ahrens, L., Wiberg, K., 2018. Micropollutants in drinking water from source to tap - method development and application of a multiresidue screening method. Sci. Total Environ. 627, 1404-1432.

Vanderleyden, J., Daniels, R., Michiels, J., 2004. Quorum sensing and swarming migration in bacteria. FEMS (Fed. Eur. Microbiol. Soc.) Microbiol. Rev. 28, $261-289$.

Vincenti, S., Quaranta, G., De Meo, C., Bruno, S., Ficarra, M.G., Carovillano, S., Ricciardi, W., Laurenti, P., 2014. Non-fermentative gram-negative bacteria in hospital tap water and water used for haemodialysis and bronchoscope flushing: prevalence and distribution of antibiotic resistant strains. Sci. Total Environ. 499, 47-54.

Wang, H., Hu, C., Shen, Y., Shi, B., Zhao, D., Xing, X., 2019. Response of microorganisms in biofilm to sulfadiazine and ciprofloxacin in drinking water distribution systems. Chemosphere 218, 197-204.

WHO, 2011. Guidelines for Drinkingwater Quality. World Health Organization, Geneva, Switzerland.

Wilson, B.R., Bogdan, A.R., Miyazawa, M., Hashimoto, K., Tsuji, Y., 2016. Siderophores in iron metabolism: from mechanism to therapy potential. Trends Mol. Med. 22, 1077-1090.

Xi, C., Zhang, Y., Marrs, C.F., Ye, W., Simon, C., Foxman, B., Nriagu, J., 2009. Prevalence of antibiotic resistance in drinking water treatment and distribution systems. Appl. Environ. Microbiol. 75, 5714.

Xie, H., Hao, H., Xu, N., Liang, X., Gao, D., Xu, Y., Gao, Y., Tao, H., Wong, M., 2019. Pharmaceuticals and personal care products in water, sediments, aquatic organisms, and fish feeds in the Pearl River Delta: occurrence, distribution, potential sources, and health risk assessment. Sci. Total Environ. 659, 230-239.

Zearley, T.L., Summers, R.S., 2012. Removal of trace organic micropollutants by drinking water biological filters. Environ. Sci. Technol. 46, 9412-9419.

Zhang, J., Li, W., Chen, J., Qi, W., Wang, F., Zhou, Y., 2018. Impact of biofilm formation and detachment on the transmission of bacterial antibiotic resistance in drinking water distribution systems. Chemosphere 203, 368-380.

Zhang, L., Li, X.Z., Poole, K., 2000. Multiple antibiotic resistance in Stenotrophomonas maltophilia: involvement of a multidrug efflux system. Antimicrob. Agents Chemother. 44, 287-293.

Zhang, S., Gitungo, S.W., Axe, L., Raczko, R.F., Dyksen, J.E., 2017. Biologically active filters - an advanced water treatment process for contaminants of emerging concern. Water Res. 114, 31-41.

Zwiener, C.,Frimmel, FH. 2004 Residues of clofibric acid, ibuprofen and diclofenac in the aquatic environment and their elimination in sewage treatment and drinking water production. In: Kümmerer, K. (Ed.), Pharmaceuticals in the Environment: Sources, Fate, Effects and Risks. Springer Berlin Heidelberg, Berlin, Heidelberg, pp. 121-132. 